\title{
Type 2 diabetes management in Hong Kong ethnic minorities: what primary care physicians need to know
}

\author{
Catherine XR Chen *, KH Chan
}

\section{A B S T R A C T}

Objectives: To identify the demographics and compare diabetes control in ethnic minority group diabetes patients with Chinese diabetes patients who are managed in primary care settings and to explore strategies to improve their care.

Design: Retrospective case series.

Setting: General Outpatient Clinic of a Hong Kong Hospital Authority hospital.

Patients: Chinese type 2 diabetes patients and ethnic minority groups who had been regularly followed up with annual assessments carried out between 1 March 2012 to 28 February 2013 were recruited. Their serum levels of fasting glucose, creatinine, estimated glomerular filtration rate, haemoglobin A1c levels, lipid profile, blood pressure, and co-morbidities were retrieved from the Clinical Management System. Student's $t$ test and analysis of variance were used to evaluate continuous variables and the Chi squared test for categorical data. All statistical tests were two-sided, and a $\mathrm{P}$ value of $<0.05$ was considered significant.

Results: Among 4346 type 2 diabetes patients fulfilling the inclusion criteria, 3966 (91.3\%) patients were Chinese and 380 (8.7\%) were from the ethnic minority groups. Compared with Chinese diabetes patients, the latter were much younger and more obese (both $\mathrm{P}<0.001$ ). Their glycaemic control was poorer than age- and sex-matched Chinese diabetes patients $(\mathrm{P}=0.006)$. Control of systolic blood pressure was similar in the two groups, but the mean diastolic blood pressure was higher in the ethnic minority groups than in the controls $(78 \pm 11 \mathrm{~mm} \mathrm{Hg}$ vs 73 $\pm 11 \mathrm{~mm} \mathrm{Hg} ; \mathrm{P}<0.001)$. With regard to lipid control, their total cholesterol, low-density lipoprotein, and triglyceride levels were similar, but high-density lipoprotein levels were much lower in the ethnic minority groups than their Chinese counterparts $(1.19 \pm 0.33 \mathrm{mmol} / \mathrm{L}$ vs $1.28 \pm 0.36 \mathrm{mmol} / \mathrm{L} ; \mathrm{P}=0.001)$. Among the five major ethnic minority groups with diabetes, Pakistani patients had particularly poor glycaemic control and the Nepalese had the poorest diastolic blood pressure control.

Conclusions: Ethnic minority groups are an integral part of the Hong Kong population. Compared with Chinese diabetes patients, those from the ethnic minorities were much younger and more obese. Deficiencies exist in the comprehensive management of diabetes in these ethnic minorities, particularly with respect to glycaemic control. Culturally tailored health care interventions are therefore warranted to promote patient education and clinical effectiveness and to improve their long-term health status.

\section{Hong Kong Med J 2014;20:222-8}

DOI: $10.12809 / \mathrm{hkmj} 134035$

CXR Chen *, MRCP (UK), FHKAM (Family Medicine)

KH Chan, FRACGP, FHKAM (Family Medicine)

Department of Family Medicine and GOPC, Queen Elizabeth Hospital, 30 Gascoigne Road, Kowloon, Hong Kong

* Corresponding author: uccxr758@ha.org.hk

New knowledge added by this stud

- Compared with Chinese diabetes patients, ethnic minority group (EMG) diabetes patients from South Asia were much younger but more obese and had higher co-morbidity from hypertension.

- In EMG diabetes patients, glycaemic control was poorer than their age- and sex-matched Chinese counterparts (mean \pm standard deviation, haemoglobin A1c $7.8 \pm 1.7 \%$ vs $7.5 \pm 1.4 \% ; \mathrm{P}=0.006$ ). Systolic blood pressure control was similar in the two groups, but the mean diastolic blood pressure was higher in EMG cohort $(78 \pm 11$ vs $73 \pm 11 \mathrm{~mm} \mathrm{Hg} ; \mathrm{P}<0.001)$. High-density lipoprotein levels were much lower in EMG diabetes patients than in the Chinese controls $(1.19 \pm 0.33$ vs $1.28 \pm 0.36 \mathrm{mmol} / \mathrm{L} ; \mathrm{P}=0.001)$.

- Among the five major EMGs of diabetes patients, Pakistani patients had particularly poor glycaemic control and the Nepalese had the poorest diastolic blood pressure control.

Implications for clinical practice or policy

- Deficiencies exist in the comprehensive management of diabetes among South Asian diabetes patients in Hong Kong. Genetic factors, obesity, insulin resistance, and poor compliance to medical advice and treatment due to multiple socio-economic factors have been postulated to contribute to this occurrence.

- Local doctors should pay particular attention to their requirements and offer flexible and integrated care that reflects their physical, psychological, social, and cultural needs. 


\section{Introduction}

Type 2 diabetes mellitus (T2DM) is one of the most common chronic conditions encountered in primary care, and affects up to $10 \%$ of Hong Kong (HK) population. ${ }^{1}$ Its complications include kidney disease, blindness, lower limb amputation, and coronary heart disease; all of which lead to increased morbidity and mortality. ${ }^{2}$

Ethnic minorities constitute an important component of the HK population. According to census in 2011, about 95\% of the local inhabitants are ethnic Chinese; the remainder (ethnic minorities) are mainly from Asia (India, Philippines, Nepal, Pakistan, and Indonesia). ${ }^{3}$ Previous studies have shown that diabetes affects certain ethnic minority groups (EMGs) differently. ${ }^{4}$ South Asians are at higher risk for T2DM by up to 4 to 6 fold compared with other ethnic groups, probably due to a combination of genetic and environmental factors. ${ }^{5,6}$ In addition, South Asians have a much higher prevalence of T2DM with cardiovascular disease that occurs at an earlier age and is associated with higher morbidity and mortality. ${ }^{7}$ Differences in health care systems, limited access to health services, and social deprivation can further compound the risk of developing diabetes and its complications.

Improving the quality of chronic disease management is an essential component of health policy in the community. Locally, a significant proportion of T2DM patients including those from EMGs are managed in primary care and followed up at government general out-patient clinics (GOPCs) of the Hong Kong Hospital Authority (HKHA). The clinic where the authors work is one of the largest GOPCs of the HKHA, and more than $50 \%$ of its attendees have chronic diseases including diabetes. In addition, it is located in central Kowloon, where most of the South Asian minorities including Indians, Nepalese, and Pakistanis reside.

Till now, local data on the diabetic control among EMG diabetes patients are lacking. To address this knowledge gap, we aimed to identify and compare the demographics of diabetes and its control in ethnic minority and Chinese patients managed in primary care and to explore possible strategies to improve care. We believe this study will provide important background information to address important issues pertinent to chronic disease management within various HK ethnic groups.

\section{Methods}

This was a retrospective case series study carried out in the Yau Ma Tei Jockey Club GOPC of the HKHA. According to a pilot study carried out in early 2012, the five major ethnic minorities undergoing regular follow-up in this clinic were from India, Nepal, the Philippines, Pakistan, and Indonesia. Regular follow-

\section{香港少數族裔二型糖尿病患者的臨床治療： 基層醫生需知}

\author{
陳曉瑞、陳景康
}

目的：檢視與比較在基層醫療診所覆診的二型糖尿病華人及少數族裔 患者的流行病學資料及糖尿病的臨床治療狀況, 並探討相關策略以改 善少數族裔糖尿病患者的綜合臨床診治。

設計：回顧病例系列研究。

安排 : 香港醫院管理局轄下一所普通科診所。

患者：於 2012 年3月 1 日至2013年2月28日期間在上述診所進行定期年 度檢查的華籍及少數族裔二型糖尿病患者均被納入本研究範圍, 並對 他們的空腹血糖、血清肌酐、腎小球濾過率、糖化血紅蛋白、血脂及 血壓控制進行分析。 $t$ 檢驗和方差分析用來分析計量資料, 卡方檢驗用 來分析計數資料。所有統計學測試都是雙邊檢定, $\mathrm{P}<0.05$ 表示數據有 統計學顯著差異。

結果：共有4346名二型糖尿病患者符合納入標準, 其中3966名 (91.3\%) 患者為華人, 另380名 $(8.7 \%)$ 來自少數族裔。與華籍糖 尿病患者相比, 少數族裔的糖尿病患者較年輕和肥胖（兩者的 $\mathrm{P}$ 值 均為 $<0.001) ;$ 他們的血糖控制明顯比年齡和性別匹配的華籍患者 較差 $(\mathrm{P}=0.006)$ 。兩組的收縮壓控制相近, 但少數族裔糖尿病患 者的平均舒張壓較華籍組為高 $(78 \pm 11 \mathrm{~mm} \mathrm{Hg}$ 比 $73 \pm 11 \mathrm{~mm} \mathrm{Hg}$; $\mathrm{P}<0.001)$ 。血脂控制方面, 兩組的總膽固醇、低密度脂蛋白和甘油 三酯的水平相近, 但少數族裔患者的高密度脂蛋白水平明顯較華籍患 者低 $(1.19 \pm 0.33 \mathrm{mmol} / \mathrm{L}$ 比 $1.28 \pm 0.36 \mathrm{mmol} / \mathrm{L} ; \mathrm{P}=0.001)$ 。五大 少數族裔中, 巴基斯坦籍糖尿病患者有較差的血糖控制, 而尼泊爾籍 糖尿病患者的舒張壓控制最差。

結論：少數族裔群體是香港人口的重要組成部分。與華籍糖尿病患者 相比, 少數族裔糖尿病患者更年輕和較為肥胖, 反映對少數族裔糖尿 病患者的綜合診治及管理上存在不足, 尤以血糖控制未見理想。本研 究建議為少數族裔群體制定有其族裔特點的綜合糖尿病診治計劃, 加 強教育宣傳, 以進一步提高臨床療效和改善少數族裔糖尿病患者的長 期健康狀況。

up was defined as returning to our clinic for chronic disease management on a regular basis, ie, every 1 to 4 months. Very few Caucasians or other Asian ethnic groups such as the Japanese and Koreans had regular follow-up at this clinic and were therefore excluded from the analysis.

\section{Subjects}

Patients with T2DM coded by International Classification of Primary Care (ICPC) T90, who had been regularly followed up at Yau Ma Tei Jockey Club Clinic between 1 March 2012 and 28 February 2013, and had an annual blood and urine checkup at least once during this period were recruited. The diagnosis of diabetes was based on the "Definition and description of diabetes mellitus" from American Diabetes Association in 2010. ${ }^{8}$ Wrongly diagnosed diabetes patients, type 1 diabetes patients, diabetes patients who were regularly followed up in the specialist out-patient departments (SOPDs), 
diabetes patients who had no annual checkup within this period, and those who were neither Chinese nor belonged to the above five EMGs were excluded.

\section{Determination of variables}

The recruited patients' age, gender, ethnicity, smoking status, body mass index (BMI), latest blood pressure, fasting blood sugar (FBS), haemoglobin A1c (HbA1c) and creatinine levels, urine albumin/

TABLE I. Demographic characteristics of diabetes patients recruited into study*

\begin{tabular}{lccc}
\hline Demographic & Chinese $(\mathbf{n = 3 9 6 6 )}$ & $\begin{array}{c}\text { Ethnic minority } \\
\text { groups }(\mathbf{n = 3 8 0})\end{array}$ & P value \\
\hline Gender & $2059(51.9 \%)$ & $205(53.9 \%)$ & 0.45 \\
\multicolumn{1}{c}{ Male } & $1907(48.1 \%)$ & $175(46.1 \%)$ & \\
\multicolumn{1}{c}{ Female } & 1.08 & 1.17 & \\
Male-to-female ratio & $66.1 \pm 11.5$ & $55.4 \pm 11.7$ & $<0.001$ \\
Age (years) & $25.8 \pm 4.3$ & $28.5 \pm 4.6$ & $<0.001$ \\
Body mass index $\left(\mathrm{kg} / \mathrm{m}^{2}\right)$ & $674(17.0 \%)$ & $80(21.1 \%)$ & 0.13 \\
\hline Smokers & & & \\
\hline
\end{tabular}

* Data are shown as mean \pm standard deviation or No. (\%) of cases

TABLE 2. Metabolic, blood pressure and lipid profile control, and renal function in Chinese and ethnic minority group diabetes patients matched with age and sex*

\begin{tabular}{|c|c|c|c|}
\hline Item & Chinese $(n=380)$ & $\begin{array}{l}\text { Ethnic minority } \\
\text { groups }(n=380)\end{array}$ & $P$ value \\
\hline BMI $\left(\mathrm{kg} / \mathrm{m}^{2}\right)$ & $26.5 \pm 4.7$ & $28.5 \pm 4.6$ & $<0.001$ \\
\hline \multicolumn{4}{|l|}{ Concomitant disease } \\
\hline Hypertension & $252(66.3 \%)$ & $280(73.7 \%)$ & 0.03 \\
\hline Stroke & $22(5.8 \%)$ & $17(4.5 \%)$ & 0.41 \\
\hline Ischaemic heart disease & $20(5.3 \%)$ & $11(2.9 \%)$ & 0.10 \\
\hline Chronic kidney disease & $62(16.3 \%)$ & $56(14.7 \%)$ & 0.55 \\
\hline \multicolumn{4}{|l|}{ Metabolic control } \\
\hline Haemoglobin A1c (\%) & $7.5 \pm 1.4$ & $7.8 \pm 1.7$ & 0.006 \\
\hline Fasting blood glucose (mmol/L) & $7.5 \pm 3.2$ & $8.1 \pm 3.1$ & 0.02 \\
\hline \multicolumn{4}{|l|}{ BP control } \\
\hline Systolic BP (mm Hg) & $133 \pm 15$ & $134 \pm 17$ & 0.41 \\
\hline Diastolic BP (mm Hg) & $73 \pm 11$ & $78 \pm 11$ & $<0.001$ \\
\hline \multicolumn{4}{|l|}{ Renal function } \\
\hline Serum creatinine $(\mu \mathrm{mol} / \mathrm{L})$ & $78.7 \pm 25.2$ & $77.2 \pm 32.6$ & 0.48 \\
\hline eGFR $\left(\mathrm{mL} / \mathrm{min} / 1.73 \mathrm{~m}^{2}\right)$ & $89.6 \pm 22.8$ & $92.3 \pm 23.1$ & 0.11 \\
\hline Urine ACR (mg/mmol) & $10.5 \pm 46.3$ & $9.1 \pm 49.2$ & 0.69 \\
\hline \multicolumn{4}{|l|}{ Lipid profile } \\
\hline Total cholesterol (mmol/L) & $4.98 \pm 1.26$ & $4.90 \pm 0.95$ & 0.42 \\
\hline HDL (mmol/L) & $1.28 \pm 0.36$ & $1.19 \pm 0.33$ & 0.001 \\
\hline LDL (mmol/L) & $2.94 \pm 1.01$ & $2.95 \pm 0.80$ & 0.50 \\
\hline Triglyceride (mmol/L) & $1.90 \pm 1.79$ & $1.76 \pm 1.37$ & 0.23 \\
\hline
\end{tabular}

Abbreviations: $\mathrm{ACR}=$ albumin/creatinine ratio; $\mathrm{BMI}=$ body mass index; $\mathrm{BP}=$ blood pressure; eGFR = estimated glomerular filtration rate; $\mathrm{HDL}=$ high-density lipoprotein; $\mathrm{LDL}=$ low-density lipoprotein

* Data are shown as mean \pm standard deviation or No. (\%) of cases creatinine ratio, and lipid profile were retrieved from the Clinical Management System (CMS) of the HKHA. The most recent blood and urine test was used for analysis if more than one test had been performed during the study period. The BMI was calculated as body weight/body height ${ }^{2}\left(\mathrm{~kg} / \mathrm{m}^{2}\right)$. The patient was considered a smoker if he/she currently smoked or was in the first 6 months of stopping.

We used the abbreviated Modification of Diet in Renal Disease ${ }^{9}$ to give an estimated glomerular filtration rate (eGFR) expressed in $\mathrm{mL} / \mathrm{min} / 1.73 \mathrm{~m}^{2}$, and chronic kidney disease was defined as having an eGFR of $<60 \mathrm{~mL} / \mathrm{min} / 1.73 \mathrm{~m}^{2}$ :

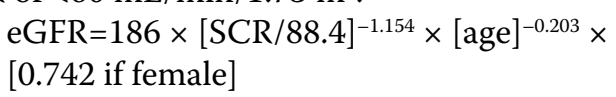

where SCR was the serum creatinine level expressed as $\mu \mathrm{mol} / \mathrm{L}$

The medical history of stroke, ischaemic heart disease (IHD), and concomitant hypertension (HT) were retrieved based on ICPC codes in the CMS. Stroke cases were retrieved using ICPC codes K89 (transient ischaemic attack), K90 (cerebrovascular accident), and K91 (cerebrovascular disease). Cases of HT were retrieved using ICPC codes K86 (uncomplicated HT) and K87 (complicated HT). Patients with IHD were retrieved using the codes K74 (IHD with angina), K75 (acute myocardial infarction), and K76 (IHD without angina). Repeat systolic blood pressures (SBPs) of $\geq 130 \mathrm{~mm} \mathrm{Hg}$ or diastolic blood pressures (DBPs) of $\geq 80 \mathrm{~mm} \mathrm{Hg}$ confirmed a diagnosis of HT in diabetes patients. ${ }^{10}$

\section{Statistical analyses}

All data were entered and analysed using computer software (Statistical Package for the Social Sciences; Windows version 16.0; SPSS Inc, Chicago [IL], US). Student's $t$ test and analysis of variance were used to analyse continuous variables and Chi squared tests for categorical data. Tukey and Games-Howell tests were used for pairwise comparisons within the five minority groups, if applicable. All statistical tests were two-sided, and a $\mathrm{P}$ value of $<0.05$ was considered significant.

\section{Results}

A list of 5536 T2DM patients followed up in this clinic from 1 March 2012 to 28 February 2013 was generated from the CMS. Among them, 1190 (21.5\%) were excluded due to the already described exclusion criteria (11 wrongly diagnosed as diabetic, 1 had type 1 diabetes, 395 were regularly followed up in the SOPDs, 2 were Caucasians, and 781 diabetes patients had no blood and urine checkup during the recruitment period). Thus, findings from the remaining 4346 (78.5\%) patients fulfilling our inclusion criteria were analysed. Among these patients, 3966 (91.3\%) were Chinese and 380 (8.7\%) were from the EMGs. Table 1 summarises the 
demographic characteristics of these patients in both the Chinese and EMGs. In summary, they were comparable in terms of gender ratio and smoking status (both $\mathrm{P}>0.05$ ). However, patients from the EMGs were significantly younger (mean \pm standard deviation [SD], $55.4 \pm 11.7$ years vs $66.1 \pm 11.5$ years; $\mathrm{P}<0.001$ ) and their BMIs were much higher (mean $\pm \mathrm{SD}, 28.5 \pm 4.6 \mathrm{~kg} / \mathrm{m}^{2}$ vs $\left.25.8 \pm 4.3 \mathrm{~kg} / \mathrm{m}^{2} ; \mathrm{P}<0.001\right)$ than those of the Chinese diabetes patients.

To reduce confounding due to age, 380 ageand sex-matched diabetes patients were randomly selected from the Chinese diabetes cohort. Table 2 summarises the glycaemic, blood pressure and lipid profile control, as well as kidney function in these diabetic Chinese and EMGs. The latter patients were found to have a greater proportion with HT than the Chinese diabetic controls $(\mathrm{P}=0.03)$, whereas their comorbidity rates for stroke, IHD, and chronic kidney disease were similar. Glycaemic control was poorer in EMG diabetes patients than their age- and sexmatched Chinese counterparts (HbA1c, $7.8 \pm 1.7 \%$ vs $7.5 \pm 1.4 \%$; $\mathrm{P}=0.006$ ). Consistently, their FBS levels were also much higher than those of the controls $(\mathrm{P}=0.02)$. With regard to blood pressure control, SBP was similar in the two groups, but the mean DBP was higher in the EMG cohort (78 \pm 11 vs $73 \pm 11 \mathrm{~mm} \mathrm{Hg}$;
$\mathrm{P}<0.001)$. When lipid control was compared, total cholesterol, low-density lipoprotein (LDL), and triglyceride levels were found to be similar in the two groups. High-density lipoprotein levels (HDLs), however, were much lower in the EMG diabetes patients $(1.19 \pm 0.33 \mathrm{mmol} / \mathrm{L}$ vs $1.28 \pm 0.36 \mathrm{mmol} / \mathrm{L}$; $\mathrm{P}=0.001)$.

Regarding the demographic characteristics of EMG diabetes patients (Table 3), most were Nepalese $(n=169)$, followed by Indian $(n=103)$, Filipino $(n=51)$, Pakistani $(n=47)$, and Indonesian $(n=10)$. The male-to-female $(M / F)$ ratio was much higher in the Pakistani, Indian, and Nepalese groups $(\mathrm{P}<0.001)$. However, the mean age of the Nepalese and Pakistani patients was much younger than that of the Indian and Indonesian groups $(\mathrm{P}=0.004)$. More Nepalese and Pakistani diabetes patients were chronic smokers than those from the other ethnic minorities $(\mathrm{P}<0.001)$.

Table 4 shows glycaemic, blood pressure, and lipid profile control in diabetes patients within the individual EMGs. Owing to their dissimilar age and gender composition, comparisons between different minority groups were inevitably confounded. Nevertheless, the data indicated that glycaemic control was particularly poor in Pakistani patients

TABLE 3. Demographic characteristics of diabetes patients in different ethnic minority groups*

\begin{tabular}{|c|c|c|c|c|c|c|}
\hline Demographic characteristics & Nepalese $(n=169)$ & Indian $(n=103)$ & Filipino $(n=51)$ & Pakistani $(n=47)$ & Indonesian $(n=10)$ & $P$ value \\
\hline \multicolumn{7}{|l|}{ Gender } \\
\hline Male & 97 & 62 & 12 & 34 & 0 & $<0.001$ \\
\hline Female & 72 & 41 & 39 & 13 & 10 & \\
\hline Male-to-female ratio & 1.35 & 1.51 & 0.31 & 2.62 & 0 & \\
\hline Age (years) & $53.6 \pm 11.2$ & $58.9 \pm 12.7$ & $56.7 \pm 9.6$ & $52.5 \pm 12.8$ & $58.4 \pm 6.4$ & 0.004 \\
\hline Body mass index (kg/m²) & $28.1 \pm 3.5$ & $28.5 \pm 5.4$ & $28.8 \pm 5.4$ & $29.4 \pm 4.8$ & $28.4 \pm 2.3$ & 0.51 \\
\hline Smoker & 43 (25.4\%) & 18 (17.5\%) & 5 (9.8\%) & 14 (29.8\%) & 0 & $<0.001$ \\
\hline
\end{tabular}

* Data are shown as mean \pm standard deviation or No. (\%) of cases

TABLE 4. Chronic disease control in ethnic minority group diabetes patients*

\begin{tabular}{|c|c|c|c|c|c|}
\hline Chronic disease control & Nepalese $(n=169)$ & Indian $(n=103)$ & Filipino $(n=51)$ & Pakistani $(n=47)$ & Indonesian $(n=10)$ \\
\hline Haemoglobin A1c (\%) & $7.8 \pm 1.9$ & $7.8 \pm 1.7$ & $7.5 \pm 1.2$ & $8.4 \pm 1.6$ & $6.8 \pm 0.6$ \\
\hline \multicolumn{6}{|l|}{ BP control } \\
\hline Systolic BP (mm Hg) & $134 \pm 18$ & $133 \pm 18$ & $134 \pm 14$ & $134 \pm 18$ & $129 \pm 15$ \\
\hline Diastolic BP (mm Hg) & $84 \pm 11$ & $75 \pm 11$ & $76 \pm 10$ & $78 \pm 9$ & $75 \pm 11$ \\
\hline \multicolumn{6}{|l|}{ Lipid control } \\
\hline Total cholesterol (mmol/L) & $4.69 \pm 0.98$ & $4.61 \pm 0.92$ & $4.87 \pm 0.93$ & $4.69 \pm 1.00$ & $5.00 \pm 0.68$ \\
\hline HDL (mmol/L) & $1.22 \pm 0.28$ & $1.14 \pm 0.32$ & $1.28 \pm 0.43$ & $1.04 \pm 0.27$ & $1.56 \pm 0.41$ \\
\hline LDL (mmol/L) & $2.72 \pm 0.82$ & $2.74 \pm 0.81$ & $2.84 \pm 0.80$ & $2.73 \pm 0.77$ & $2.72 \pm 0.64$ \\
\hline Triglyceride (mmol/L) & $1.71 \pm 1.16$ & $1.66 \pm 1.50$ & $1.69 \pm 0.79$ & $2.26 \pm 2.10$ & $1.60 \pm 0.50$ \\
\hline
\end{tabular}

Abbreviations: $\mathrm{BP}=$ blood pressure; $\mathrm{HDL}=$ high-density lipoprotein; $\mathrm{LDL}=$ low-density lipoprotein

* Data are shown as mean \pm standard deviation or No. (\%) of cases 
(mean \pm SD HbA1c levels being $8.4 \pm 1.6 \%$ ), and less so in the Nepalese and Indian groups $(7.8 \pm 1.9 \%$ and $7.8 \pm 1.7 \%$, respectively). In contrast, the metabolic control of Indonesian diabetes patients was generally satisfactory (mean HbA1c level being $6.8 \pm 0.6 \%$ ). The mean SBP was similar among all EMGs, but the mean DBP control was suboptimal in the Nepalese group $(84 \pm 11 \mathrm{~mm} \mathrm{Hg})$ and within target in the other minority groups. When lipid control was studied, the total cholesterol, LDL, and triglyceride levels were similar, but Pakistani patients had a much lower mean HDL level $(1.04 \pm 0.27 \mathrm{mmol} / \mathrm{L})$.

\section{Discussion}

This study was the first clinical analysis of T2DM patients in local EMGs. It compared demographic characteristics of both Chinese and EMG diabetes patients managed in primary care. Notably, it revealed discrepancies between the groups in terms of glycaemic, blood pressure, and lipid profile control.

Notably, in HK, the basic demographic features of Chinese diabetes patients and those from EMGs were quite different. The latter were younger and more obese; such findings were in line with those in the HK census in 2011 which showed that $61.3 \%$ of EMGs were aged 25 to 44 years and that the median age for all EMG patients was much lower than that of the entire $\mathrm{HK}$ population. ${ }^{3}$ In addition, the main reason for staying in HK for nearly all EMG subjects was to work, and when asked about their occupation most of the recruited EMG diabetes patients $(n=334$, or $87.9 \%$ of them) stated that they undertook manual labour. Thus, most were in their $40 \mathrm{~s}$ and $50 \mathrm{~s}$ and therefore their mean age was understandably younger than that of their Chinese counterparts (identified within a gradually ageing population). Furthermore, diabetes patients from South Asian ethnicities were more obese and had a much higher BMI than their Chinese controls. It is well known that the prevalence of obesity varies substantially between ethnic groups and is estimated to differ according to the precise measurements used (eg BMI, waist-to-hip ratio, and waist circumference). Although no data in the literature have directly compared the BMI of Chinese diabetes patients with that of those from South Asia, studies from UK have revealed that the mean waist-hip girth ratios and trunk skin folds were larger in South Asians than in European and Chinese groups. ${ }^{11}$

Since age is a very important confounder that prevented direct comparison between the two groups, age- and sex-matched diabetes patients from the Chinese and ethnic minorities were studied further. Even so, glycaemic control was poorer in EMG patients than the matched Chinese controls (mean $\pm \mathrm{SD}, \mathrm{HbA} 1 \mathrm{c} 7.8 \pm 1.7 \%$ vs $7.5 \pm 1.4 \%$;
$\mathrm{P}=0.006)$. Whereas SBP control was similar, the mean DBP was higher in the EMGs $(\mathrm{P}<0.001)$. In addition, the mean HDL levels were much lower in EMGs than in the matched Chinese controls $(\mathrm{P}=0.001)$. Possible reasons for such a difference between could be multi-factorial. First, several studies have shown that genetic factors may play a determinant role. ${ }^{12,13}$ Diabetes patients from the South Asia appear more likely to have insulin resistance and a higher prevalence of obesity and metabolic syndrome, all of which are chronic conditions that challenge glucose metabolism. ${ }^{5}$ Second, patients from EMGs are often at a socio-economic disadvantage and difficult to reach via mainstream channels, and so they face inequalities in accessing medical care. ${ }^{3}$ For example, EMG diabetes patients might not have their diabetes diagnosed if they were socially disadvantaged and might be less inclined to seek medical care. Moreover, underdiagnosed individuals may be more likely to have poor diabetic control and experience early mortality. Third, the first language of South Asian groups is usually neither English nor Chinese, and therefore they may not understand the medical advice properly. Lastly, their cultures, religious beliefs, and lifestyles may influence their behaviour (including levels of physical activity and food choices), all of which affect health status and management. Coordinated efforts are therefore needed to overcome these limitations and embark on integrated diabetes monitoring and surveillance programmes in such EMGs.

We also need to be aware that a large proportion of diabetes patients followed up at public GOPCs are from lower-income groups and the geriatric populations. Younger Chinese T2DM patients might be more inclined to seek help from Specialist Clinics and private doctors. Thus, these findings might not be directly applicable to private or other specialist settings. Nevertheless, the present findings suggest important groundwork for further local and international studies.

The demographic characteristics of diabetes patients within EMGs indicated that their gender ratios also varied dramatically. Among Filipino patients, the $\mathrm{M} / \mathrm{F}$ ratio was 0.31 and all Indonesian patients were female. By contrast, most Pakistani, Indian, and Nepalese diabetes patients were male ( $\mathrm{M} / \mathrm{F}$ ratios being $2.62,1.51$, and 1.35 , respectively). These findings were consistent with a thematic report on ethnic minorities in the $2011 \mathrm{HK}$ population consensus, which showed considerable variations in the gender composition of different ethnic groups in the community ${ }^{3}$; the $M / F$ ratios of Indonesians and Filipinos were extremely low but the ratios were converse among Pakistanis and Nepalese. This was because large proportions of Filipinos and Indonesians in $\mathrm{HK}$ were foreign domestic helpers, of whom $99 \%$ were female. ${ }^{3}$ On the 
contrary, most Nepalese and Pakistanis worked in elementary occupations such as at construction sites or as security guards, and most were males. This difference in gender composition also contributed to a greater proportion of Nepalese and Pakistanis being chronic smokers as compared with the other Asian minorities. As the different age and sex distributions among EMGs was an important confounder of clinical outcomes, no direct comparison on diabetes control between different subgroups was feasible. Nevertheless, we found that Pakistani diabetes patients had particularly higher HbA1c levels and lower HDL concentrations. Indeed, studies have shown that the epidemiology and determinants of diabetes in Pakistan reveal a peculiar combination of risk factors. ${ }^{13}$ Strong genetic and environment factors interplay along with in-utero programming, in the context of low birth weights and gestational diabetes contributing to a high prevalence and poor control of T2DM in Pakistanis. ${ }^{14}$ On the other hand, Nepalese diabetes patients had suboptimal DBP control. This finding is in line with World Health Organization reports that Nepal has a high burden of HT and that the blood pressure control rates have been poor due to the inadequate awareness and lack of proper treatment. ${ }^{15,16}$ Local doctors should therefore pay particular attention to the needs of different ethnic groups and offer a flexible care package that reflects their physical, psychological, social, and cultural needs and at the same time upholds their autonomy, dignity, privacy, and personal choice.

Diabetes is a significant problem among both the Chinese and EMGs in HK. It is important that government officials, clinicians, and allied health workers understand the evidence and implement strategies to address shortcomings actively. Our local practice has emphasised empowering people with diabetes to support their own care management by proper diet control and active lifestyle strategies. In addition, concerted efforts are needed to raise awareness of diabetes and disseminate prevention messages to high-risk groups in collaboration with their community opinion leaders. Nowadays, information, interpretation, and advocacy services have been provided in HKHA clinics, which is definitely a positive step towards improving understanding of the disease among ethnic minority patients. Meanwhile, our services should assimilate aspects of ethnicity and culture, and implement culturally specific interventions to improve diabetes control in HK EMGs.

\section{Implications to the primary care}

Family physicians are at the forefront of T2DM management, and aim to achieve optimal metabolic control to prevent macro- and micro-vascular complications. This study provides important background information on the demographic characteristics of diabetes patients from certain EMGs as compared to Chinese diabetes patients. Since certain South Asian groups tend to have poorer glycaemic control, culturally tailored health care interventions are required to improve their general health and chronic disease management.

\section{Study limitations}

One limitation was that only diabetes patients who were regularly followed up in a single clinic and had annual blood and urine checkups were studied. Second, the ethnic composition in other clinics and elsewhere in HK might differ considerably. Third, patients who were followed up at this clinic but never attended for annual assessment $(n=781,14.1 \%)$, whatever the reason, were excluded and must have given rise to a selection bias. However, we have compared the major epidemiological characteristics including age and gender of such patients and found that there were no obvious differences between them and the studied patients $(\mathrm{P}=0.45$ and $\mathrm{P}=0.60$, respectively). Fourth, all variables were measured at least once during the 1-year study period, and if more than one blood test was performed, the most recent result was used for analysis. Therefore, variability of measurements might have confounded the findings. Fifth, the relatively small sample size of certain EMG subgroups and their age and gender distribution discrepancies prevented direct comparison of their metabolic control. Nevertheless, the present results may lay the groundwork for similar studies in the future both locally and internationally. Lastly, concomitant chronic diseases (HT, IHD, and stroke) were retrieved via the ICPC code in the CMS, and so inadequate ICPC coding may have underestimated co-morbidity rates in both Chinese and EMG diabetes patients.

\section{Conclusions}

Ethnic minority groups are an integral part of the HK population. Compared with Chinese diabetes patients, EMG diabetes patients were much younger and more obese. Deficiencies existed in their understanding of diabetes management, particularly glycaemic control. Culturally tailored health care interventions are therefore necessary to promote patient education and clinical effectiveness for these patient groups and improve their long-term health.

\section{Acknowledgements}

We extend our gratitude to Dr King Chan for his continuous inspiration and support during this study. We also thank Ms Elise Chan, EA III of Department of Family Medicine and GOPC, for her patience during data entry and Mr Carl Chak, statistical officer of Queen Elisabeth Hospital, for his expertise and support in data analysis. 


\section{References}

1. Chan JC, Malik V, Jia W, et al. Diabetes in Asia: epidemiology, risk factors, and pathophysiology. JAMA 2009;301:2129-40.

2. Leung GM, Lam KS. Diabetic complications and their implications on health care in Asia. Hong Kong Med J 2000;6:61-8.

3. Hong Kong 2011 population census thematic report: ethnic minorities. Available from: http://www.statistics.gov.hk/ pub/B11200622012XXXXB0100.pdf. Accessed Dec 2012.

4. Abate N, Chandalia M. The impact of ethnicity on type 2 diabetes. J Diabetes Complications 2003;17:39-58.

5. McKeigue PM, Shah B, Marmot MG. Relation of central obesity and insulin resistance with high diabetes prevalence and cardiovascular risk in South Asians. Lancet 1991;337:382-6.

6. Khan NA, Wang H, Anand S, et al. Ethnicity and sex affect diabetes incidence and outcomes. Diabetes Care 2011;34:96-101.

7. Gholap N, Davies M, Patel K, Sattar N, Khunti K. Type 2 diabetes and cardiovascular disease in South Asians. Prim Care Diabetes 2011;5:45-56.

8. American Diabetes Association. Diagnosis and classification of diabetes mellitus. Diabetes Care 2010;33(Suppl 1):S62-9.

9. Levey AS, Bosch JP, Lewis JB, Greene T, Rogers N, Roth D. A more accurate method to estimate glomerular filtration rate from serum creatinine: a new prediction equation. Modification of Diet in Renal Disease Study Group. Ann Intern Med 1999;130:461-70.

10. Chobanian AV, Bakris GL, Black HR, et al. Seventh report of the Joint National Committee on Prevention, Detection, Evaluation, and Treatment of High Blood Pressure. Hypertension 2003;42:1206-52.

11. Gatineau M, Mathrani S. Obesity and ethnicity. Available from: http://www.noo.org.uk/uploads/doc/vid_9444_Obesity_ and_ethnicity_270111.pdf. Accessed Jan 2011.

12. Gupta M, Singh N, Verma S. South Asians and cardiovascular risk: what clinicians should know. Circulation 2006;113:e924-9.

13. Rees SD, Britten AC, Bellary S, et al. The promoter polymorphism $-232 \mathrm{C} / \mathrm{G}$ of the $P C K 1$ gene is associated with type 2 diabetes in a UK-resident South Asian population. BMC Med Genet 2009;10:83.

14. Samad S, Fatima J, Asma M. Prevalence of diabetes in Pakistan. Diabetes Res Clin Pract 2007;76:219-22.

15. WHO STEPS Surveillance: Non Communicable Disease Risk Factors Survey. Kathmandu: Ministry of Health and Population, Government of Nepal, Society for Local Integrated Development Nepal (SOLID Nepal) and WHO; 2008.

16. Sharma D, Bkc M, Rajbhandari S, et al. Study of prevalence, awareness, and control of hypertension in a suburban area of Kathmandu, Nepal. Indian Heart J 2006;58:34-7. 